\title{
Interview
}

\section{The five pillars of project management infrastructure - An interview with Glenn Ferrell}

\begin{abstract}
Glenn Ferrell
has over two decades of technology and manufacturing experience, the majority of this spent with RR Donnelley's Technology Center. He has managed projects in industrial energy, competitive intelligence, robotics, continuous improvement and software development, including Donnelley's first production Digital Asset Management system. Additionally, he has served in a series of Director roles, managing Digital Content Technology, Process Technology, Digital Systems and Automation, and also on RR Donnelley's Manufacturing, Continuous Improvement and Marketing Councils. While managing project managers and Black Belts involved in everything from Software Engineering to Six Sigma and Lean initiatives. Ferrell also served as an internal consultant in new business development and technology strategy, annually presenting to Donnelley's executive team. He has degrees in Architecture, Engineering Science and Computer Science and is a certified Project Management Professional (PMP). He lives in Glen Ellyn, Illinois, where he consults on Project Management and Process Infrastructure, serves on the Board of Overseers for Illinois Institute of Technology's College of Applied Technology, and occasionally plays Old Time music at various historical venues.

ABSTRACT How has project management become especially relevant in the business context of today? Michael Moon interviews Glenn Ferrell on the history of project management, strategies for executive decision support and project portfolio management, possible applications of prediction markets and on the problems of innovation and knowledge/history retention during an economic downturn.
\end{abstract}

Journal of Digital Asset Management (2010) 6, 83-96. doi:10.1057/dam.2010.9

Keywords: project management; project management infrastructure; innovation; lean; Six Sigma; scheduling

Correspondence: Glenn Ferrell

263 Sheffield Lane,

Glen Ellyn, Illinois 60137,

USA

E-mail: gcferrell@aol.com
MM: We are here with Glenn Ferrell. Let's start off with a little bit of your background. GF: Michael, I've managed projects across several different fields including industrial energy systems, software development, industrial automation and process improvement. I've also worked in new business development, technology strategy, competitive intelligence and on marketing and manufacturing councils, as well as doing a couple of stints on Balanced Scorecard teams. I spent the majority of my career in the RR Donnelley Technology Center.

MM: Right. Perhaps you can bring us up the speed in terms of your current practice, what you focus on, and the types of engagements and the details.

GF: Currently I consult on project

management, project management infrastructure and project portfolio management strategies. I'm particularly interested in working with smaller companies who are just starting to form their strategies or who are simply struggling with the problems of how to keep their projects on track and how to get the best return on their overall project portfolio investment.

The statistics I'm seeing indicate that only about 40 per cent of projects succeed. Given the tremendous demands on a company's bottom line in this economy, that just doesn't work.

MM: It sounds like a great place to start. Glenn, if you would give us a short historical survey of project management, its roots and perhaps some of the major phases which it has gone through, bringing us up to the current day?

GF: Well, there are a couple of different ways to attack that. A history of projects is really sort of the history of civilization. It is a history of the way people interact in groups. However, when project management people talk about the history of project management, they are usually 
talking about project management tools and the way project management tools and processes have been used.

MM: Before you go further, I'd like to examine the concept that projects represent another mechanism of culture - how we propagate from one generation to the next, a set of values, norms, expectations, beliefs and behaviors. And so, like great art or food or architecture, project management is right up there in terms of another vehicle mechanism of culture by which we kind of create the future.

GF: Very well said.

MM: So when most people talk about projects, they are talking about project tools or project management tools, correct?

GF: Probably so. But to really understand project management I think we should probably start with defining what a project really is and what it isn't. Then we might touch on history and work our way up to tools.

So first, as you know, projects are temporary and always produce unique results. Those results are generally a new product, a new service or some type of cost reduction. Projects are not ongoing operations. If something repeats and/or creates non-unique results it is not a project. It is an operation.

Secondly, projects are always progressively elaborated. At the beginning of a project we really don't understand the scope or the details of how the thing is going to be executed. That understanding develops as we move through analysis, design and implementation. Also, as this understanding develops, the outside world is not standing still. So, scope changes are normal and part of a project that must be managed and integrated effectively. So progressively elaborated means that as project details become increasingly specific and as scope changes are requested and approved, the project becomes increasingly detailed and complex.

The third point is that projects are always cost-constrained. I have never seen one that isn't.

And finally, although there are single-person projects, when we talk about project management we are talking about managing multiple stakeholders. By stakeholders, I mean the project team, customers, vendors, contractors, executive management and so on. So, since the projects we're concerned with have multiple participants or stakeholders, we have the associated problems of communication and division of labor in a large group.

So the type of project we are interested in is temporary, delivers unique results, is progressively elaborated, is cost constrained and requires coordination of many stakeholders.

MM: Okay.

GF: So on to the history, tools and mechanisms of project management. Since projects are temporary and have start and end dates, the first tool we have to have is scheduling. Scheduling has a lot of military history. Sun Tsu discusses it in the Art of War and Xenophon discusses it in The Persian Expedition. The complexity of many projects of the ancient world implies that they used diagrammatic tools and graphics. Julius Caesar built a bridge across the Rhine in 14 days, while outnumbered and in hostile territory. To accomplish that, there had to be some guy in a tent with ink, parchment and abacus doing some pretty sophisticated scheduling - and he probably wasn't just adding columns of Roman numerals. But graphics in general don't survive the copying process. Scribes learned to copy characters but archeologists believe that very few learned to draw, so the history of those ancient tools is pretty much lost.

So we have to wait until modern times to talk about graphical or diagrammatic scheduling tools.

The first important one was the Gantt chart. Frederick Taylor developed scheduling boards in the last half of the 1800s. You still see these in a lot of factories. Henry Gantt worked with Frederick Taylor in the steel industry and then further developed these ideas while he was working in ship-building during World War I. After the Gantt chart was instrumental in the success of the Hoover Dam in the ' 30 s and the Interstate Highway Project in the '50s, it became a standard part of the project management toolkit.

Also in the mid-'50s, we see CPM (the Critical path Method) and PERT (Program Evaluation and Review Technique) charts being developed simultaneously. Dupont was looking for something useful to do with a Univac and they developed CPM in conjunction with a naval special projects office. This improved on the Gantt chart by allowing activities to be 
organized in a network so that the project manager could focus on the critical path within that network. Despite the fact that CPM reduced Dupont's project shutdowns by about 25 per cent, they abandoned it, probably because of a management change around 1959. Somehow CPM as a tool survived, but this story always makes me wonder if there is a graveyard of good tools out there that were abandoned because of management changes or just applying the wrong tool to the wrong problem.

MM: Right. Glenn, what is contemporaneous with this is that we have a whole branch of mathematics that began to support these modern advanced notions of logistics and operations research. Am I right?

GF: Right. Statistics and probability mathematics are probably the most important. It may be a good time to talk about the probability when we get into risk management - one of the elements of project management that we want to discuss.

MM: So, in the context of the history of projects and project management, looking at tools and methods, we have identified two traditions. First, we have operations research and logistics, how to ensure when you put 50000 soldiers into a battle theater, you got enough food, tents and bandages. And, second, from a branch of applied mathematics and rigorous ways of synchronizing scarce resource with better schedules and deployment configurations. GF: We are in the 1950s, and the Navy has the challenge of building the first nuclear submarine, the Polaris. They bring in Booz Allen and together they develop the PERT technique.

The PERT technique provides both estimating and scheduling capabilities. So, it adds this estimation capability to the scheduling capabilities that CPM provides. Today, people use these terms interchangeably, but PERT has estimating methods that are used by many project management professionals.

Critical Chain Project Management (CCPM) adds resource flexibility between tasks, which can sometimes accelerate the overall schedule. This technique tends to be more dynamic than PERT/CPM. It is relatively new and evolved out of Goldratt's Theory of Constraints.

That covers the most significant scheduling tools. Let's move on to risk. If projects are progressively elaborated then, as we move left to right down the timeline, complexity is increasing and there are always unknowns to the right of wherever we are. Complexity and unknowns imply a risk of failure.

Risk management is fundamentally based on probability theory. The beginnings of probability theory start in the renaissance and then are further developed by Blaise Pascal when he starts to think about gambling. Christian Huygens, a friend of Pascal, wrote the first book on probability theory in the early 1600 s - again, on the subject of gambling.

Huygans was Dutch and during this period the Dutch and English are involved in a lot of trading, commerce, shipping etc, not to mention a war or two. About 30 years after Huygans' book there is this coffee shop in London where captains get together to exchange information on hazards, routes and weather. That shop is 'Lloyds of London', which gradually evolves into the great insurance company. Insurance companies largely become the green houses where probability theory develops up to the point where we see it today.

MM: Which is to say, when lots of money became involved, the practice really accelerated in terms of both the mathematics in the underlying theory as well as various applications of that mathematics.

GF: Exactly. Another Dutch innovation is 'options'. Risk was already being hedged with options in Amsterdam by the 1700s. Project managers still have to hedge their risks. For instance, if you are dealing with a foreign project, it involves some kind of currency exchange. Your job is not to speculate in the currency market. Your job is to hedge your risk so that the fluctuations in the currency market do not affect the outcome of your project's financials. So the concept of options plays a part in risk management.

MM: Before we get in to the application of these historical terms and developments to business, I wanted to circle back on one area, because it is such a rich conversation that I wanted to give it more than just a passing notice. That is the notion of scheduling. Scheduling, I imagine, has many different implications if it is related to a project. For example, let's look at the difference in scheduling for a project, which you indicated as 
something has a beginning, middle, and ending and a unique result - versus scheduling for operations, which you described as structured, ongoing and repeatable. Can you elaborate a little more on scheduling and how it relates to project management infrastructure?

GF: Okay, first off, projects deal with uncertainty so, for example, every task in a PERT chart has an optimistic, pessimistic and realistic duration, and there is specific mathematical process by which you estimate the overall duration of the critical path. Operations schedules have less uncertainty and generally don't do anything this complex.

Secondly, a good project management infrastructure not only supports improvement of project management but also supports abstraction so that executive decisions are easier to make. This abstraction includes schedules. So, ideally, subproject schedules are 'nested' in project schedules, projects in programs and so on, so that you can look at things at higher levels of abstraction as you go up to the big picture. A project manager will create a schedule that is made up of activities which are connected in a network fashion. However, a program manager will deal with multiple projects and will probably want to relate all of those projects, perhaps in some kind of a high level Gantt chart. Then if he wants to drill down on those projects, he probably wants to look at elements of the work breakdown structure (WBS) instead of actual activities. For the program manager, these WBS elements are containers for all the underlying activities.

So, initiatives can be organized in several abstraction layers: Program, Project, Sub-project, for example. A large corporation may also have some type of construct on top which contains Programs and Processes. In this context, a Process is a specific manufacturing process like material handling, pre-assembly, finishing and so on. These processes are operations-related and a process manager may manage both a single manufacturing process and a number of projects which are individually intended to make some change or improvement to that process. This is usually where the Six Sigma and Lean projects go. For companies that organize their projects this way, the goal would be for executive management to be able to see both Programs and
Processes at the same time, in order to make economic tradeoffs.

MM: Now, this has profound implications as we look at digital supply chains and digital systems where we have business process management platforms that facilitate dynamic scheduling - as well as practically self-organizing projects.

GF: Right. Individual project scheduling is always dynamic within the constraints of end dates and milestones. But programs become more dynamic when the external environment changes. So, rapid changes in the economy, new technologies, mergers or acquisitions cause projects to be dropped or reshuffled within a program. With all that change it would be almost impossible to make informed executive decisions without the recent developments in online project analytics. In a company with a solid project management infrastructure, these project analytics systems allow management to drill down through these layers and focus attention on the most critical areas.

MM: So that would be the third large vector?

GF: Exactly. We think about this 'big picture' activity as being performed by executives but, in keeping with our discussion on history, it used to be performed by monarchs. There is a chart in one of Tufte's books from the 1780s showing the balance of trade in England. On the facing page there is a horizontal bar chart which drills down specifically on imports and exports to Scotland. So Monarchs could drill down from a big picture to detail just like executives can today. The chief differences are speed, accuracy and flexibility.

MM: And perhaps, as you have just said, it represents someone who has responsibility for the realm, someone who has an overall sense of accountability for making sure that that things move through his realm in ways that are most advantageous to the crown.

So you could say that this is the digital lineage of project management, the first lineage being centered on organizing the logistics of warfare and then later, on the industrial operations.

Second, we have the mathematics of the underlying theory that enables one to calculate schedules, probabilities and so on.

Then the third, originally designed, as you said, from the point of view of the king looking at his realm, but then increasingly senior 
executives who are concerned with overall performance of an organization, not necessarily the status of a project or program.

GF: Right. That is a fair summarization, although we might want to just mention two more components of the project management process.

First, the fact that a project is cost constrained leads us to issues of cost accounting that is, cost tracking and estimating and budgeting because there is a whole raft of tools underneath those areas which have very rich history. For the most part these tools have been appropriated by project management from other disciplines.

MM: So, if you will, that would be the fourth pillar of project management infrastructure is the cost and the time, cost, and the money - which you could say in this construct money really represents discrete units of time.

GF: Right, and saving time, or getting to market earlier with your product or improvement could mean either increased revenue or increased savings or both. Then the fifth pillar would be related to managing and communicating with all of the stakeholders including project staff, contractors, customers, vendors, operations management, executive management etc.

MM: Fabulous. So there we have the five pillars of projects, project management and therefore the foundation of a project management infrastructure.

GF: Right.

MM: How about if we take that then into a business context? Specifically, how has project management become especially relevant in the business context of today?

GF: Well, one of the things that we have seen within the last couple of decades is the growth of PMOs around the country because managers have begun to recognize what I mentioned before - that only about 40 per cent of projects actually achieve their objectives. Ideally, a wellrun Project Management Office (or Program Management Office) (PMO) should increase the probability that an individual project will succeed and increase the visibility into the risk that an individual project will fail. This is important so that failing projects can be shut down early and resources can be reallocated somewhere else.
For this to work, a project must go through some kind of a 'stage-gate' process which allows you to decide at each individual stage whether to kill it or continue to fund it. That stage-gate process has to be managed by someone - a sponsor, a program manager or a project management office. The stage-gate review is kind of like a submarine surfacing. Between reviews, projects tend to 'run under the water' and to be much less visible to management.

And there has to be some kind of infrastructure that allows the training of project managers, the training of sponsors and the training of program managers, so that this process is smooth and works effectively. The group generally manages both stage-gate reviews and this project-process training is the PMO. But there are many different ways to do this and, in smaller companies, there are ways to do this without a full-time organizational construct. MM: In the last 15 years or so, we have seen the flattening of organizations. Some people have called it the hollowing out of middle management, which from a macroeconomic perspective has the job of filtering, refining and transforming data and the information and information and insights that then become the basis for management and leadership to lead and manage the organizations.

GF: Right.

MM: So the flattening of organizations is now accelerated by recent economic troubles. What role does project management have in helping companies adapt more quickly to the changes, many of the external and macroeconomic in nature?

GF: Okay. When markets shrink, as they are shrinking now, a company needs a big picture perspective in order to make intelligent tradeoffs. We talked about a high-level view of both programs and processes before. In a shrinking market, it may make more sense for a company to cut a project or program that is developing a new product or service - rather than make cuts to projects which are supposed to cut cost from an existing 'Process'. So this should be an executive's first focus - can the market still absorb the product or service this project is producing. However, as the situation worsens, executives are faced with cutting process improvement projects and finally (or 
simultaneously) with thinning middle management ranks in order to survive.

This creates challenges. I have talked to several directors who now have a 100 and more direct reports whereas before they had anywhere from 10 to 30 . With this many reports, a director has no time to mentor and coach project managers and managers. But the more critical problem is that they have a great deal of difficulty tracking what is going on. MM: Glenn, it is even exacerbated by the fact that we have e-mail and remote offices, with telecommuters and so on. That makes the whole notion of management even more challenging because you know you are not physically sharing the same space.

GF: Right. And one of the problems that is at least partially solved by good project management is communication overload.

Because as you are aware, communication tends to increase exponentially as the number of individuals in a particular communications context grows. A good project manager controls communications by putting processes into place that structure those communications so work can proceed effectively. Actually, stage-gate reviews contribute a lot to this goal because they help minimize ad hoc project reviews that drain project resource.

MM: So, we want more than to just control it. Rather we want to add information flows, so that the remaining flows are of the highest quality and/or applicability in terms of the recipient? Right?

GF: Right. Communication control is necessary in order to aggregate and summarize those flows, and now I think we are beginning to come to the next level. If projects are still being managed by project managers in a sort of an eclectic way, where project tracking, estimating and scheduling are all done in fairly unique ways by each individual project manager, then summarizing progress for a higher-level view becomes very complicated. Does that make sense?

MM: Makes complete sense.

GF: Because of this complexity, the lack of middle management layers and because of the sheer labor or aggregating and summarizing progress, the information passed to management is generally of very poor quality. This makes it more difficult to see major risks and problems.
MM: So, if we start to develop the business context of project management, we see:

1. Companies are still doing projects and in many cases they are doing more projects, generally with a shorter duration, by larger numbers of people.

2. Companies still structure repeatable programs.

GF: Right, although the current economic situation has undoubtedly resulted in a fairly massive project culling, that is the long-term trend. And you are also right that companies are many times embedding repeatable operations activity under the name of 'projects'. That's very cost inefficient and it tends to unnecessarily inflate the overall cost of a project management infrastructure.

Another effect of the current economic situation is that there are certain categories of projects that are shrinking and types that are growing.

MM: Such as?

GF: Well, until markets start to grow again, the first category of project I think we are seeing culled in this current crisis is new product development. Then as the economics continue to get more challenging we will see (or in many cases, have already seen) the culling of process improvement projects, Six Sigma, Lean etc. Then, as we discussed, comes the organizational flattening, elimination of middle management etc. MM: And why is that?

GF: In my experience, the product development projects are culled first because markets are collapsing, either due to the economy or disruptive technologies. Let's look at the print market. Web and cable TV were disruptive technologies to the print industry. When those technologies started to absorb advertising dollars the print markets had not really begun to collapse yet, so the printing industry responded by initiating a raft of new technology projects. These projects included everything from bar-coding cell phones for catalogue ordering to printing circuits on paper.

Lots of interesting technologies were either being discussed, were in an R\&D stage or in real development. Then the market truly began to shrink and those technology projects (new product/new process projects) were culled 
and that capital and cash was then routed to continuous improvement projects that were intended to cut cost - implemented through Six Sigma and Lean type methodologies. This made sense but required a new process management infrastructure, complete with training, process managers, Black Belts etc. The problem was the market collapse was accelerating and the continuous improvement projects couldn't save enough cost to compensate. Any industry that services rapidly shrinking markets must consolidate. So the money for continuous improvement had to be rerouted to mergers and acquisitions.

So in this case, disruptive technologies resulted in new product programs. Those were abandoned when markets began to shrink and funds were rerouted to cost reduction projects. When the market collapse accelerated - forcing industry consolidation - cost reduction projects were abandoned to fund mergers and acquisitions, which also further flattened management layers. I would expect this same pattern has occurred in dozens of industries. MM: Makes complete sense - say you have a particular project management infrastructure that you must have in place in order to speed post-merger of newly acquired divisions or subsidiaries of the firm. A big project with a lot of risk and upside!

GF: Okay.

MM: And ultimately where many mergers and acquisitions run into problems is around the IT infrastructures, the ability for IT infrastructure to accommodate that level of systemic change.

GF: Absolutely.

MM: Can you speak to that?

GF: Sure. Three things. First, at least in a typical large manufacturing company, I don't think anyone truly understands the diversity of an IT infrastructure before they buy the company. So integration costs, schedules and risks are almost always underestimated. Secondly, those systems were implemented to replace human processes that may have operated very differently from those of the acquiring company. There can be profound differences in data schemas between the two companies. It may not be practical or even possible to translate all of this into a common data architecture. And third, many of the only people who understand all of the reasons that things are the way they are have either left or are leaving the company. This is a huge loss of knowledge to the company.

With regards to the overall IT project portfolio, another important issue arises. The loss of CEOs, executives, middle management means a huge loss of knowledge to the company and, more specifically, a loss of insight into the project portfolio. It is quite likely that the new management will want to reshuffle this portfolio. If the acquired company had a PMO (Project or Program Management Office) and if it still exists, you may have the information necessary to make intelligent decisions about that portfolio. However, if no 'knowledge repository' like this still exists, there is very little information on which to base these decisions and they tend to be driven by the internal politics of the acquiring company. Additionally, if there are now two PMOs there will be significant and probably appropriate pressure to merge them. This adds another variable to the problem.

To make intelligent decisions you have to be able to see projects in a way that evaluates both the financial and risk characteristics for every single project. Then you manage the whole as you might an investment portfolio. You can't do this without the appropriate infrastructure.

These are the basic problems with corporate 'marriages'. There are many interesting strategies for dealing with them. Sarbanes-Oxley is obviously one of the greatest motivators for getting this right.

MM: Right. Well, this sounds like a great place to then really build out in a more formal way what we call a project management infrastructure. So, what are some of the basic components and frameworks for such an infrastructure?

GF: From a process standpoint, you first need to have a project or program management office which maintains the process infrastructure for project and program management. This office has to drive enough standardization so that executives can have much more summarized view of projects throughout the company. Remember that standardization is necessary if we want to aggregate and summarize information across projects and programs. MM: So, a project management office then really does two things: one is to provide a common set of tools and frameworks for 
defining and running projects and, perhaps just as importantly, to provide a set of reporting tools that produce uniform data information that can be aggregated and summarized up through activities and tasks all the way up to business process.

GF: Right. Additionally, they provide educational services both to sponsors, project managers and sometimes to executives. Also, the $\mathrm{PMO}$ is responsible for the project history or knowledge repository. Even though it is hard to quantify, this repository has huge value to a company. Unfortunately, these repositories generally either don't exist or are not searchable. Financial data and many other types of data generally have a home in a data warehouse somewhere. This is not usually the case for historical project management data. Without having an organization like a PMO it is difficult to retain project history. Without history, you can't learn from your mistakes or even make good decisions on how to proceed with new projects.

MM: Right. Glenn, that also gets to an idea I would like you to develop. I had introduced the idea of an organizational historian, you know the one of two people in a company who simply made it kind of their personal job to study, observe and classify how we, in this company, do things. These organizational historians know the ins and outs of the firm's culture norms, lessons learned and how things get done.

In many respects, organizational historians become the softer, more feminine side to the harder, most masculine aspects of project management office that structure and codify a lot of those cultural norms and learnings. GF: Yes, when you mentioned this concept I immediately thought of data architects. You know, people who oversee an organization's data and who know how they all fit together. These are very unique characters. They have an understanding of how all of the data schemas within all the databases in the company fit together and also how they map to the business and to the business needs. I think it may be almost as important to have people who understand the how a company's business processes map together.

MM: Well, that is just a process, but the unspoken norms as conveyed by stories right? You know, 'If you want to do that, then so- and-so has to be part of the conversation and if he or she is not part of the conversation that will become a show stopper or at least stand in the gears of progress'.

GF: Right. Good example. All our financial data may be data-warehoused and searchable but a great deal of important knowledge (including what you call stories) is only warehoused in and searchable by, specific people.

MM: Well, it also neatly syncs up with what you just said. It is like you have a data architect. We might even have corollary in digital asset management as it relates to metadata and, specifically, metadata associated not just with, you know, rich media in a massive repository, but other forms of metadata relate to information, IT service policies, configurations of IT resources and so on.

And in particular, I remember having a conversation with one of the 'wild duck' at IBM in the research group. We had a conversation around creating a database for no other purpose than warehousing metadata and database schemas; where you might treat metadata as simply another data type within the database.

We really got going with the idea that a metadata repository might enable one to build a new application or repository through a set of queries to the metadata database, thereby assembling new schemas so you could then understand or model of a new workflow or business processes, as well as understand how the new application or service would sink up to existing applications and IT infrastructure. Did I make sense, and if so could do go on that?

GF: Yes, the concept that comes to mind is a cultural schema that could help a project manager understand where to find relevant information on the culture and history of a company. The Project Management Institute recommends that a project manager performs a historical and cultural investigation of the company at the very beginning of a project to improve his chances of success. Wouldn't it be nice if there were someone analogous to a data architect that he consult to figure out where to start?

MM: Right, and again, organizational historians tend to be the informal repositories of that cultural knowledge.

GF: That is a very interesting concept

Michael, and I would love to get more insight 
in what kind of processes a cultural historian might use.

MM: Well, I had it related to me by Dr Garry Hare, now the professor of the School of Media Psychology at Fielding Institute. He shared with me that organizational historians are the individuals who have worked in that particular company you know 5, 10, 20 and 25 years. Many do not have some meaningful executive position; in fact almost all were not in a position of leadership or authority.

He went on to say that organizational historians position themselves in or around interesting things going on, like the deployment of the major new ERP system or a transformation of the business process or a wholesale redesign of the factory floor or the institution of the new work real policy that is enterprise-wide.

Some of them will make meaningful contribution as a member of staff to these projects, but unlike people who simply just got stuff done, organizational historians kept detailed mental notes, in some cases physical notes of who did what and how and if not why not. GF: Right. It sounds like a fascinating role and, to play devil's advocate a bit, it sounds like a role that is at great risk in an organization. For example, I managed a competitive intelligence project for a Fortune 250 company. I took a team of cross-market marketing directors (subject matter experts) and facilitated them through the construction of a business/ competitive intelligence process that would be generally effective across all of their markets. We documented the process, developed a database and applications and hired a manager to run the process. This worked very effectively for a couple of years. Of anyone in the company, this manager had the best handle on all of the competition within the industry. However, when the industry was downsized and consolidated, he was one of the first to go. I think a cultural historian faces the same risk, especially if there is not some other missioncritical role to which he or she is also attached. The value of cultural history is difficult to quantify.

MM: Well, I think that is true in one respect and yet I think collectively we have responded in a way that offsets many of the downsides of what you just described. In particular, the importance of creating conversational microsites or portals where an organization has taken upon itself to talk to itself about how it does things. Thus, while individuals will move on the ways of understanding and doing things remains set in a social, conversational context.

GF: Good. So you institutionalize a little bit of knowledge management to be able to absorb it.

MM: Right. And the mental maps by which we collectively think and get things done - you could say that those mental maps are another form of unstructured metadata, as it relates to knowledge that lives in the human beings that work there.

GF: Right. We have a challenge when we talk about collapsing organizations and collapsing middle management. If you think of people in a company as analogous to routers in a network, they have access to many resources on a lateral basis, who have organizational knowledge and who know how to go to those people and retrieve that knowledge. With the flattening of management hierarchies, many of the lateral links among middle managers tend to break and become more narrowly vertically. As a result communications tend to only move up and down between management and their direct reports. The value of all of that horizontal interaction tends to get lost.

MM: Right. It seems to me that it also then gets redistributed to your network of suppliers and partners.

GF: Yes, that is a good point.

MM: And so it seems to me that another dimension of project management infrastructure is really how to access subject matter experts that may have worked for the time, but now have found gainful employment in the industry and specifically among your vendors and partners.

GF: Right. That becomes an important goal. MM: Glenn, in the spirit of really developing out a project management infrastructure, could you just bring us up to speed in terms of some major frameworks from models for management process-control frameworks such as Lean, Six Sigma and things like that.

GF: Sure, I managed a group of project managers and Black Belts running both Lean and Six Sigma projects when those efforts were first initiated at Donnelley. Lean is an interesting animal because although you can have lean 
projects, lean also implies an overall transformation of the organization. In this transformation, lean is ultimately pushed down to the shop floor and becomes part of the operations process. Generally this 'goal' of achieving a lean organization takes many years to accomplish. A lean project may be formulated to move an organization towards this goal, or a lean project may be a project that simply uses lean tools to perform some specific process improvement.

So there may be a threshold to cross at some point in time. When you initiate Lean programs in the organization, you usually initiate them with a series of pilots. These pilots are projects. However, as your shop floor employees begin to become Lean practitioners on an everyday basis, we have to make case-by-case decisions on what efforts should be projects and what things should simply be folded into operations. MM: Yes.

GF: So lean is something which generally starts as projects. To push it down into operations requires shop floor training programs and some strategy on how to gradually operationalize the expertise and redirect the project management organization's attention to another area.

MM: So, what are the basic operating principles of Lean as you understand it, in this context? GF: Well, the primary operating principle of Lean is to shrink inventory to nothing. To give you an example: 'print rolls' in the print industry. Traditional 'logs' (or large horizontal strapped stacks of signatures) take a great deal of labor to handle and feed into bindery hoppers. A 'print roll' can be loaded with signatures directly from the end of the press, and then it is picked up by one fork lift driver who can move it to a bindery hopper and, by herself, attach it. However, print rolls take much more space than logs and, being expensive, you can afford less of them. Because of these two facts, once print rolls were installed at this plant they were forced to implement Lean because there was insufficient storage to store work in process. The technology acted as a Trojan horse for a Lean transformation that stretched all the way back through the supply chain.

MM: Lean, as I understand, it originally originated in the application of Deming's principles around total quality management by Toyota.
GF: Right.

MM: And some of the ideas of Lean are simple, which is first to start off with an end-to-end depiction of a business process or set of workflows, identifying who does what and how it, and you know, what are the critical decision points or handouts.

GF: Right.

MM: And then in the course of doing that and trying to eliminate as many steps as possible as a function of looking at more intuitive or direct ways of getting the results produced in sequence. GF: Right. One of the key Lean tools to do this process-mapping and time-compression activity is called Value Stream Mapping.

MM: And then in addition to that, once we have a framework, we then start pushing the responsibility for controlling the flow down to the individual, such that you make quality his or her personal job; so that you really start optimizing with the flow from the bottom up, as opposed to simply by management fiat, top down; where the management forces people to make all manner of tradeoffs and, ultimately, induces workers to produce more defects and other negative unintended consequences.

GF: Right. That is an excellent summary. With the capability of stopping the line, the individual can ensure that the problem and perhaps even the process are fixed before the product becomes part of finished goods - and therefore require more extensive rework. This is fundamentally the same relationship software quality assurance (QA) has to software testing. QA focuses on preventing the problem, while testing typically catches it after the fact. Both Lean and software QA have a strong focus on reducing cycle time. Both are based on Deming and the Japanese tools that implemented his principles.

MM: Right. And we know that by reducing the steps in any one process, you also reduce cycle time. A reduction of cost can lead to greater outputs given the right infrastructure, incentives and processes. Did I understand right? GF: Right, very good.

MM: Then, Six Sigma is, if you will, a different complementary approach?

GF: Yes. Both Lean and Six Sigma are 'process improvement' approaches. Both have similar waste reduction goals. However, Six Sigma is never completely pushed down to the shop 
floor operator. It tends to remain a project approach because the skill sets, including a strong grasp of statistics, are difficult to master. So although the results of a Six Sigma project the specific process improvement - will be continued by the shop floor crew after the project is completed, it is unlikely that the shop floor crew has the ability to start a new Six Sigma project.

Another difference is that the Six Sigma DMAIC model (Define, Measure, Analyze, Improve and Control) is, in practice, very analogous to the scientific method. So the model tends to produce a real cause and effect understanding of the problem. This means that the quality of the knowledge gained during the Six Sigma project tends to be greater than the knowledge gained during a Lean project.

The more technologically intensive and complex the process to be improved is, the more I would lean towards Six Sigma. (However, there sometimes comes a point - especially in IT projects - where a Black Belt just has the wrong set of tools to tackle the problem.)

Both Lean and Six Sigma processes require a training infrastructure. Both may require various levels of certification. Lean training has to be implemented from shop floor through management. Six Sigma has to be implemented from Green Belt level through management. MM: Yes.

GF: So the training infrastructure for either Six Sigma or Lean may be organizationally analogous to that implemented by the PMO. Likewise, the historical or knowledge infrastructure of a good Six Sigma or Lean organization should be analogous to that of the PMO. It is just as critical to retain the history and results of all Six Sigma projects as it is to save the history and results of all IT projects.

By the way, I use 'PMO' as convenient shorthand. In smaller companies, many of the functions of a PMO might be performed by other mechanisms and organizational structures. Additionally, I don't think PMOs necessarily have to be run by the IT organization.

To compare Six Sigma to other forms of Project Management, the DMAIC model of Six Sigma is very similar to the 'stage-gate' approach that a PMO would implement with IT projects. A sufficiently sophisticated PMO should be very comfortable with managing a set of Six Sigma projects. The chief challenge would be that the project management skill set of a certified PMP tends to be higher than that of a certified Black Belt. The Black Belt project management toolset tends to be a simplified subset of what is normally expected of a certified project manager. Generally, this simplification works fairly well for Six Sigma type projects. On the other hand, PMOs should probably have little to do with classical Lean initiatives. I think these should probably be run entirely out of operations.

MM: Right. We have also seen a convergence of Lean and Six Sigma. Are there any other extemporaneous management process control frameworks that you find especially relevant to IT infrastructure readiness and/or project management infrastructure, in particular as it relates to IT service management and IT service delivery?

GF: Yes. Are you familiar with Analytical Hierarchy Process (AHP)? AHP is used by the Pentagon and by companies and institutions around the country at the very front end of projects and programs and processes. AHP significantly improves complex decision making, whether the decisions have to do with overall company strategy or portfolios of projects. AHP can be used at any level within the company.

I've used this with teams of Business Unit Presidents and Senior Vice President (SVPs) on a multi-million dollar company-wide program, and also with engineers and shop floor managers on much smaller projects.

With AHP, a group creates hierarchies of their goals and then, generally moving from parent to child layers, quantitatively weights the relative importance of those goals. Goals are then related to programs or projects; relative weightings are developed to determine the degree to which specific projects drive specific goals etc. Ideally this starts at an executive level and trickles down to lower levels where goals may be progressively elaborated. The implementation of this has to be customized to the business, so it requires a trained facilitator. Since Quality Function Deployment (QFD) is a critical component of AHP, it helps if the facilitator is certified or at least trained in QFD. You need real QFD as described by Mizuno and Akao. Unfortunately, there are 
'misappropriations' of QFD that don't work well with this process.

There are also some specialized software tools to help with this that easily save enough time to pay for the investment.

It is hard to really summarize this. You have to see it in action to get a real sense of its power. Because the process is done in groups, there is a kind of 'honesty' to it that tends to override individual political agendas.

Oh! and one more thing about managing project portfolios: at least one of the tools that support AHP has add-ons that support the 'efficient frontier' concept for a project portfolio. This makes it easier for management to evaluate entire sub-portfolios of projects against one another. So let's say you have a fixed budget for your overall portfolio and too many projects, this helps to arrange projects in groups and position them on a risk/reward graph, so that management can decide which groups of projects to fund.

MM: Let's expand on the notion of decision markets or prediction markets - the application of game theory and a system using incentives to predict strategic outcomes.

In particular, would you speak to how prediction markets might relate to your discussion of options analysis and value stream analysis? And, perhaps, you can address the need to get a sufficiently large group with a necessary level of cognitive diversity within the group to make their best guess as to the probability of a particular event occuring.

GF: Okay. I haven't seen prediction markets in action, although many current techniques use a subject matter expert-driven 'voting' technique to weigh relative risk, importance or potential duration. We mentioned AHP, QFD, but Failure Mode and Effects Analysis and the Delphi estimating technique are other examples.

MM: So, usually it is a point in time with a stated probability of that particular thing occurring. Then you have people use funny money or micropayments of 10 cents, to make bets or buy warrants; that particular thing will happen, right?

GF: Yes.

MM: And so the stock market is one big prediction market in terms of one company's best estimate among all of the stakeholders and shareholders, a best estimate as far as future free cash flows of one firm versus another, right?

GF: Right, right.

MM: Okay. So let us take that same concept and apply it to product optimization and media mix optimization. One of the problems that many organizations have today is where best to spend my marketing dollars.

GF: Right.

MM: And as you can well imagine that represents a rather significant and growing conundrum for many companies. So we could then create an options market around very specific media placements and/or points of engagement and then have a company, a large company and perhaps its trusted partners then make bets in terms of which media mix, product mix, optimization will get the best results: lift in sales with lowest number of returns and therefore the most profitable.

So, if you will, we are talking about creating a prediction market where we ask stakeholders across the organization to make their best guess in terms of which media strategy will produce the best results.

GF: So the market participants would be stakeholders within the organization. Then, I would think, for a small organization with stakeholders who are 'experts' you might get an output similar to that of the Delphi technique.

MM: Let's get to the underlying idea of prospectively discounting future free cash flows as a way to calculate the economic value of an otherwise intangible asset. We might use a set of discount factors derived from a prediction market; where you have asked people to estimate what would be the impact of this particular discount factor on our ability to achieve those revenue goals. A discount factor might include taking a fully operational DAM offline: how much revenue would the firm lose? GF: It is a fascinating idea. All you need are mechanisms to manage the prediction market and a critical mass of knowledgeable 'traders' with a motivation to participate. I know that there have been some efforts to provide a 'prediction market' for project milestones, where the project stakeholders place bets on when these milestones will occur. I would guess that at the project portfolio level, something like this could be used to look at the risk of particular external events that might affect the overall 
portfolio. This might already be happening but I'm not aware of it. Then there is the question on the degree to which the prediction market itself might affect the outcome. There's definitely a lot to think about.

MM: As we are beginning to wrap up our interview here, would you speak to the idea of innovation leadership and specifically what you see emerging as the next practices of innovation? Particularly in these constrained economic times, with the emergence of these project management infrastructure?

GF: Although there are always bright spots, Apple comes to mind, I think currently we are seeing a decline in innovation, you know, not just a lack of innovation, because of these collapsing management layers and because the communication lines are getting more vertical between reports and management. Too much workload and too little time to think out of the box.

MM: Could you compare product innovation, which largely is a function of exploiting new OEM technologies from your upstream suppliers, and process innovation, which often times remain internal to the business. And if you can, address business model innovations and social innovations - all within the context of projects and how project management infrastructure supports or hinders innovation. GF: Which makes perfect sense because I believe innovation does not happen unless a context either exists or can be created for it. Let's start with product innovation. There are many examples which indicate that innovation only occurs when a need exists. For example, water power was not extensively used to drive mills, lathes etc. until the Plague had wiped out a significant percentage of the manual laborers in Europe. In the current economy, consumers have pulled back spending and the number of Stock Keeping Units (SKUs) is being cut back at retail and commercial levels. This tends to indicate that there is less need for new products and that the context for product innovation is just not there. With Process Innovation, I think the context may be that (1) a need exists and (2) tools or methods to explore that need are accessible and (3) enough 'space' has been created to allow time for that exploration. After layoffs, when two or three jobs have been folded into one, employees have the need to streamline the process but don't have the training or time to work on it. Business Model innovation is harder to talk about because an economic downturn can disrupt current business models and force new thinking in this area. So we are still seeing innovation in social media, mobile devices etc. and there are probably many other innovations we haven't seen. Also, some of these Business Model Innovations can drive new Product and Process Innovation.

Now, do project management infrastructures support or hinder innovation? I don't think that 'fostering innovation' is an important part of the mission of project management infrastructures. I think they are more focused on accomplishing the goals of management as effectively, efficiently and economically as possible. That being said, there is a lot that enlightened leaders in this area can do to create a context for innovation. Providing training that helps people 'think out of the box' really helps in this area. Help people see relationships - bring in speakers, establish cross-fertilization relationships with companies outside of your industry, introduce folks to lateral thinking, mindmapping, influence diagrams, data flow diagrams etc. Introduce your best engineers to Triz. Get some of your best analysts certified in QFD. Make sure things like strategy maps, if they exist, are getting shared down the right level. If they don't exist do some strategy mapping to get a sense of the big picture. In my experience the budget for all of this tends to be in R\&D organizations but I think, in a sufficiently enlightened organization, it could possibly exist in a PMO. In the future, something like this might be budgeted in an 'Innovation Office' run by a 'Chief Innovation Officer'.

In general, consumers have reigned in their spending because the financial crisis has reduced both jobs and personal wealth.

And so, companies have become overly survival-oriented. You might look at Maslow's needs hierarchy and position a company in that model. Many if not most companies have been down in the survival and basic needs area. Getting to the social needs area, which is next level up, is a challenge. Classically the organization who is the protector of the social needs in a company is the HR organization. After all of this organizational flattening the HR 
organization is more 'webified' than it's ever been. So, employees interact with their HR organization through a screen instead of through a human being. That is a big concern for me. So, I think before you can get to innovation, you have to be able to move up through that social layer up into the self-actualization layers and you cannot do that if you are focused on survival and on basic needs.

As job losses bottom out and the economy begins to grow, then we should begin to see some opportunities for putting more innovation process in place. However, I'm guessing that will take the form of new or transformed organizational structures. Praveen Gupta has done some very nice thinking in this area. Perhaps we build part of that structure around the new role of a 'Chief Innovation Officer'.

MM: It kind of goes to something that I remember reading, you know, one of the great books by Edward Deming in which he says the level of innovation in a company and virtually correlates to the amount of fear in the company. 'The more fearful a company, the less innovative it is'.

GF: I agree completely.

MM: And it really kind of goes to the notion that innovation inherently has some risks to it, but the risk is largely related to change in the status quo and therefore a lot scrutiny. I wholeheartedly concur that some companies are in a better situation to be able to innovate as a function of being simply less fearful or higher on the high act of actualization.

GF: I agree. Although a good deal of the innovation investment may not have a measurable return, companies who don't invest in innovation can't adapt to change.

MM: Any summarizing comments?

GF: Well, we talked about the history and some of the tools of project management. Most of that history has been focused on the planning functions, but I think that we are going to see a lot more activity in the monitoring and controlling functions, as a direct result of the flattening of management layers. That means more or better PMOs - or the organizational equivalent - to standardize tracking and reporting processes and the implementation of web-enabled project and program analytic systems to aggregate information to higher levels of abstraction and allow drill downs to specific areas of concern.

We discussed decision support. In general, our decision-making processes are fairly poor and emotionally driven. I know this is an unpopular view. There are tools and processes that make a huge difference in the quality of executive decision making and in the buy-in on those decisions after they are made. I think we are just on the threshold of the opportunities these tools provide. This is a good function to be driven out of a corporate Strategy Office or by a Chief Innovation Officer. IT is not the place for this.

I think new product development has to come from a stronger economy and stronger balance sheets. I'm hoping unemployment has bottomed out so that economic growth over the next few years will allow us to collectively climb out of 'Maslow's basement' (survival mode.) As we get more revenue growth I would expect we will see some new organizational structures and processes put in place to better support innovation. I would like to see more Chief Innovation Officers. I think it takes this level of professional to help drive a more nation-wide dialog on this subject. We need to re-examine our educational system here too. In a global marketplace innovation is a national issue.

MM: Wonderful. Great place to conclude. Thank you so much.

GF: Thank you, Michael. It was fun. 